\title{
Synthesis of micro- and nanostructures with controllable composition in the chain plasma-chemical reactions initiated by the radiation of a powerful gyrotron in the mixtures of metal-dielectric powders
}

\author{
N.N. Skvortsova ${ }^{1,2},{ }_{2}$ N.S. Akhmadullina ${ }^{3}$, G.M. Batanov ${ }^{1}$, V.D. Borzosekov ${ }^{1,4}$, L.V. Kolik ${ }^{1}$, \\ E.M. Konchekov ${ }^{1,4}$, N.K. Kharchev ${ }^{1}$, A. A. Letunov ${ }^{1}$, D. V. Malakhov ${ }^{1,4}$, E.A. Obraztsova ${ }^{1,2}$, \\ A. E. Petrov ${ }^{1,4}$, K.A. Sarksian ${ }^{1}$, V.D. Stepakhin ${ }^{1,4}$, O.N. Shishilov ${ }^{5,6}$ \\ ${ }^{1}$ Prokhorov General Physics Institute, RAS, Moscow, Russia, mukudori@mail.ru \\ ${ }^{2}$ National Research Nuclear University MEPhI, Moscow, Russia \\ ${ }^{3}$ A.A. Baikov Inst. of Metallurgy and Material Science, Moscow, Russia \\ ${ }^{4}$ Pirogov Russian National Research Medical University, Moscow, Russia \\ ${ }^{5}$ Institute of Fine Chemical Technologies, Moscow, Russia \\ ${ }^{6}$ O3-Innovation, LLC, Skolkovo Innovation Center, Moscow, Russia
}

The report presents a new type of exothermic chain reactions initiated by powerful microwave radiation of gyrotron in mixtures of metal-dielectric powders. In this microwave-plasma-chemical process new substances are synthesized with controlled composition [1]. Chain selfsustaining reactions in which initially appearing products take part in the formation of new products are the basis of many technological processes of synthesis of substances. Chain reactions occur usually at a high rate, and often have the character of an explosion [2].

Ceramic materials are widely used in modern technology so they receive wider attention of the researchers due to their unique mechanical and physical properties. Plasma methods are among the most promising techniques for the synthesis, modification, and processing of micro- and nano-structured ceramic materials [3]. There have been many examples of nanostructured material syntheses using various discharge types: spark, arc, glow, high-frequency, microwave, and so on. However, gyrotrons, being one of the most powerful sources of microwave discharges, have not been used in the regarded technology for a long time. This report will show the synthesis of -structures with controllable composition in chain reactions in powder mixtures: $\mathrm{Mo}+\mathrm{B}, \mathrm{Mo}+\mathrm{BN}$, $\mathrm{Ti}+\mathrm{B}, \mathrm{W}+\mathrm{B} . \mathrm{A}+-\mathrm{AlN}, \mathrm{Mg}+\mathrm{AlN}+\mathrm{Al}_{2} \mathrm{O}_{3}$, etc.

Experiments were carried out with stand-mounted plasma-chemical complex of the MIG-3 installation with the gyrotron (frequency $75 \mathrm{GHz}$, pulse duration up to $12 \mathrm{~ms}$, power up to $550 \mathrm{~kW}$ ) [4]. A specially designed plasma-chemical reactor (Fig. 1) [5] was placed between two mirrors of the MIG-3 quasi-optical tract.

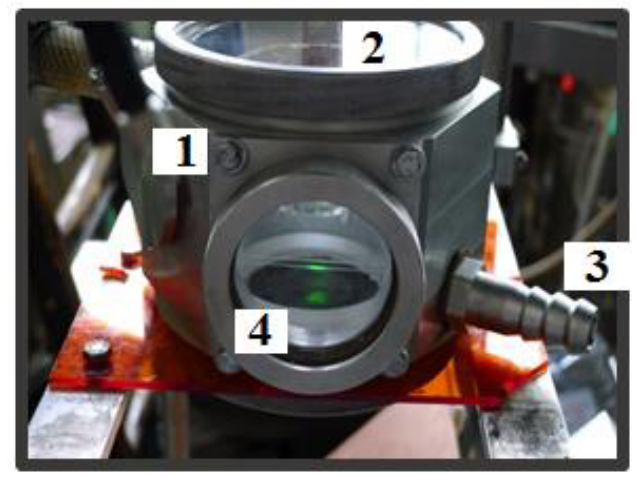

Fig. 1. Plasma chemical reactor: 1 -chamber, 2 -exit window, 3 - vacuum nozzle, 4 - diagnostic window
Microwave breakdown in the reactor was effected in the mixture of metal and dielectric powders placed on a quartz substrate with free upper surface (fig. 2). A quartz tube was set inside the reactor to collect the synthesized substances for further analysis. The evolution of direct and reflected gyrotron power during the microwave discharge was monitored using a system of microwave detectors, which were calibrated using the calorimeter [6].

The samples were prepared in the following way: 1-mm-thick layer of dielectric powder (2) (fig. 2) was put on the quartz plate (1) followed by a $0.5-0.7 \mathrm{~mm}$ layer of metal-dielectric powder mixture (3). The layers were some squeezed with a flat quartz plate and quartz cylinder (6) was set up. The upper surface of the powder remained open to ensure free plasma-gas-dynamic scattering of reaction products as well as movement of the heated gas into the quartz cylinder volume.

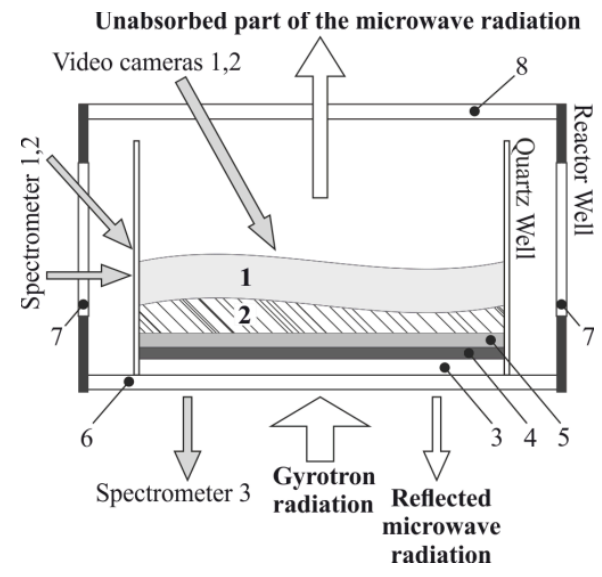

Fig. 2. General scheme of the reactor and measurements: 1 working gas, 2 - plasma, 3, 6, 8 - quartz plates, 4 - dielectric powder layer, 5 - powder mixture of metal and dielectric, $6-$ quartz cylinder $(\mathrm{d}=70 \mathrm{~mm}, \mathrm{~L}=350 \mathrm{~mm}), 7$ - diagnostic window. The arrows on the left-hand side indicate directions along which measurements were carried out by two cameras $(\# 1,2)$ and three spectrometers $(\# 1,2,3)$

The gyrotron microwave radiation was injected through the bottom quartz plate. Irradiation of the samples was carried out with 5-100 single 2-12-ms pulses with intervals no less than $20 \mathrm{~s}$. The gyrotron radiation power was $250-450 \mathrm{~kW}$ which corresponds to intensity of $\sim 6-10 \mathrm{~kW} \cdot \mathrm{cm}^{-2}$ inside the powder mixture. The synthesized substances were deposited on both the walls of 
the quartz cylinder and the remaining surfaces of the reactor including the upper quartz window. The produced materials composition and structure were analyzed using Raman spectroscopy, X-ray diffraction, energy dispersive microanalysis, transmission and reflection electron microscopes.

Previously it was shown that to transform the initial mixture of powders into a new material the gyrotron discharge parameters should be chosen so that the microwave discharge was followed by an afterglow phase. Only under these conditions absorption of microwave radiation is almost complete in the powder mixture, and followed by initiation of chemical reactions of synthesis of substances. In described experiments certain threshold values of pulse duration, gyrotron power and metal content in the every powder mixture should be found and reached.

Plasma-chemical chain reactions were observed in the atmosphere of air/nitrogen for mixtures of different metals (titanium, molybdenum, aluminum, and est.) with boron, boron nitride and other dielectrics without and in the presence of small amounts of $\mathrm{C}_{2} \mathrm{~B}_{10} \mathrm{H}_{12}, \mathrm{NaBH}_{4}$ and $\mathrm{H}_{3} \mathrm{BO}_{3}$ as hydrogen sources.

In our experiments we found all three stages of the evolution of chain process.

The first stage - initiation takes place in the upper layer of the powder during the gyrotron pulse (Coulomb explosion process) with arising its temperature up to $1 \mathrm{eV}$. Than dust particles, atoms and ions pushed out of the upper surface into the reactor.

The second stage - synthesis of complex molecules under conditions of a large temperature gradient over the height of the reactor and in the presence of ensembles of dust charged particles (dusty plasma). This stage time reaches tens of seconds. The self-oscillating character of such reactions and the increase in the yield of reaction products using a catalyst was found. Properties of ensembles of dust particles (tracks, velocities, lifetime, etc.) were measured. Photo of the ensemble of dust particles that appears in the volume of reactor $32 \mathrm{~ms}$ after turning of the gyrotron pulse is shown in Fig. 3.

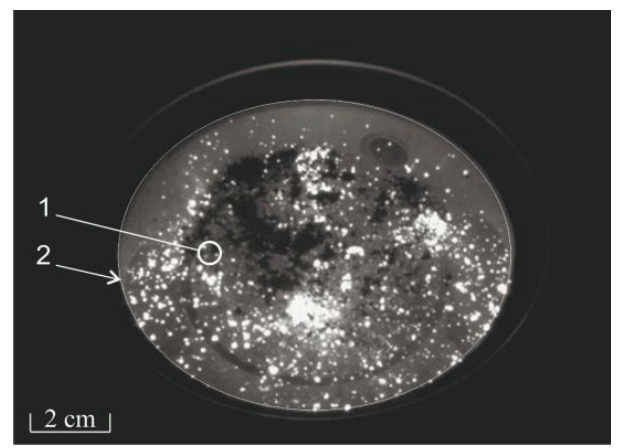

Fig. 3. Dust particles (1) in the reactor on $32 \mathrm{~ms}$ after switching off the $300 \mathrm{~kW} 2-\mathrm{ms}$ gyrotron pulse $(\mathrm{Ti}+\mathrm{B}$ powder mixture with catalyst $\left.\mathrm{H}_{3} \mathrm{BO}_{3}\right) .2$ - quartz cylinder wall

The third stage - deposition of substances on the centers of crystallization with the formation of composites of micro- and nano-sizes, spraying on the walls, cooling of substances in the reactor, stopping the chain process. A typical spherical structure synthesized in the chain reactions initiated in the mixture $\mathrm{Ti}+\mathrm{B}$ with catalyst $\mathrm{H}_{3} \mathrm{BO}_{3}$ is represented in Fig. 4. This spherulite consists of titanium nitride and titanium oxide and has a developed surface.

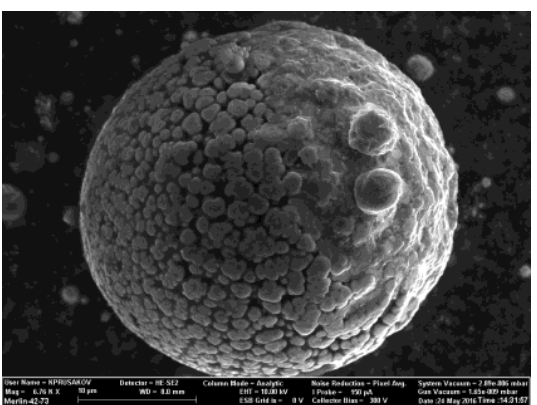

Fig. 4. Spherulite consists of titanium nitride and titanium oxide. $300 \mathrm{~kW} 2$-ms gyrotron pulse

We observed plasma-chemical processes in the $\mathrm{Al}_{2} \mathrm{O}_{3}$ + AlN mixture with $5 \%$ of $\mathrm{Mg}$ adding in the discharge under $8 \mathrm{~ms}$ pulses of $350 \mathrm{~kW}$. Formation of well-cut microcrystals of $\mathrm{MgAl}_{2} \mathrm{O}_{4}$ was confirmed by $\mathrm{SEM}$ and $\mathrm{XRD}$.

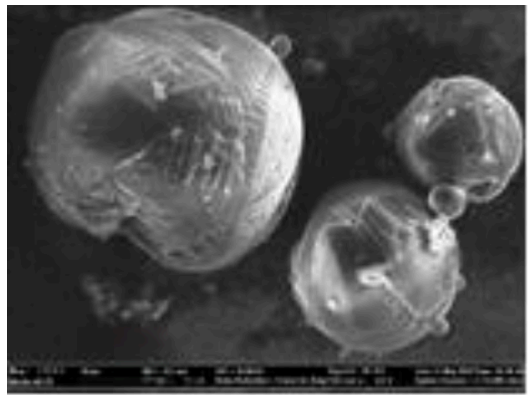

Fig. 5. Microcrystals of $\mathrm{MgAl}_{2} \mathrm{O}_{4}$ (powder mixture $\mathrm{Al}_{2} \mathrm{O}_{3}+\mathrm{AlN}+5 \% \mathrm{Mg}$ )

We are grateful to Russian Foundation for Basic Research for financial support (project \#17-03-00630-a).

\section{References}

1. Batanov, G.M., Borzosekov, V.D. et al. Microwave method for synthesis of micro- and nanostructures with controllable composition during gyrotron discharge. // J. Nanophotonics, 2016, 10(1), 012520 .

2. Semenov, N.N. // Development of the theory of chain reactions and thermal ignition. Moscow. 1969.

3. Ivanovskii A.L. Non-carbon nanotubes: synthesis and simulation // Russ. Chem. Rev. 2002. V.71. No. 3. P. 175-194.

4. Batanov, G.M., Belousov, V.I., Bondar, Yu.F., et al. // A New MIG-3 Gyrotron Complex for Creation and Heating of Plasma in the L-2M Stellarator and the First Experimental Results. Plasma Physics Reports, 2013, Vol. 39, No. 13, pp. 1088-1095 2013.

5. Skvortsova, N.N, Stepakhin, V.D., Malakhov, D.V., et al. Relief Creation on Molybdenum Plates in Discharges Initiated by Gyrotron Radiation in Metal-Dielectric Powder Mixtures // Radiophysics and Quantum Electronics. 2016. V. 58. No. 9. P. 701-709.

6. Ukryukov, G.V., Malakhov, D.V., Skvortsova, N.N., et al. // Microwave absorption in the gyrotron discharge ibn a mixture of powders of metals and dielectrics in the mode of installation of exothermic chemical reactions. Engineering Physics. 2017. No. 2. P. 28-36. 